\title{
Implicaciones de la distribución espacial del mercado de transporte colectivo en una ciudad intermedia argentina. Área Metropolitana de Mendoza
}

Implications of the Spatial Distribution of the Public Transport Market in an Intermediate Argentine City. Metropolitan Area of Mendoza

Implicações da distribuição espacial do mercado de transporte coletivo em uma cidade intermediária argentina. Área Metropolitana de Mendoza

María Emilia García Schilardi ${ }^{\star}$

Recibido: 26 de septiembre del 2019

Aprobado: 21 de abril del 2020

https://doi.org/10.12804/revistas.urosario.edu.co/territorios/a.8278

Para citar este artículo:

García Schilardi, M. E. (2021). Implicaciones de la distribución espacial del mercado de transporte colectivo en una ciudad intermedia argentina. Área Metropolitana de Mendoza. Territorios, (44), 143-170. https://doi.org/10.12804/revistas.urosario.edu.co/territorios/a.8278

* Consejo Nacional de Investigaciones Cientificasy Técnicas (CONICET). Correo electrónico: mariaemilia-garcia@hotmail. com ORCID: https://orcid. org/0000-0003-46738142 
Palabras clave

Ciudad intermedia; mercado de transporte colectivo; movilidad; sustentabilidad.

Keywords Intermediate city; mobility;

collective transport; sustainability; market.

Palavras-chave

Cidade intermediária; mobilidade;

transporte coletivo; sustentabilidade; mercado.

\section{territarias 44}

\section{RESUMEN}

Las ciudades intermedias cumplen una importante función de integración territorial y mediación entre diversos centros urbanos, con la ventaja de tener características deseables para la sostenibilidad. Considerando que el sistema de movilidad se configura como un componente clave del sistema urbano que favorece y posibilita el desarrollo sostenible, resulta de gran valor abordar el estudio del medio de transporte colectivo en este tipo de territorios. Este trabajo genera aportes para mejorar la operación de ese servicio en una ciudad intermedia argentina, teniendo como objetivo conocer la distribución espacial del mercado de transporte colectivo en el Área Metropolitana de Mendoza. Se emplea una metodología cuantitativa, a través de técnicas estadísticas y cartográficas. Los resultados indican que la mayor porción del territorio presenta una situación de mercado de equilibrio, lo cual implica que en los periodos de mayor demanda existe una necesidad de desplazamientos insatisfecha, acentuada en la periferia urbana.

\section{ABSTRACT}

Intermediate cities fulfill an important function in territorial integration and mediate between various urban centers, counting on the advantage of desirable characteristics for sustainability. Considering that the mobility system is a key component of the urban system, that favors and enables its sustainable development, it is of great value to study of the collective transport system in these territories. This work generates contributions to improve the operation of this service in an intermediate city in Argentina, with the objective of knowing the spatial distribution of the collective transport market in the metropolitan area of Mendoza. A quantitative methodology is used, through statistical and cartographic techniques. The results indicate that in the major portion of the territory the market operates in equilibrium, implying that in the periods of greatest demand there is an unsatisfied need, accentuated in the urban periphery.

\section{RESUMO}

As cidades intermediárias ou limítrofes, cumprem uma importante função de integração territorial e mediação entre diversos centros urbanos, com a vantagem de contar com características desejáveis para a sustentabilidade. Considerando que o sistema de mobilidade se configura como um componente chave do sistema urbano e que favorece e possibilita seu desenvolvimento sustentável, se faz necessário abordar o estudo do sistema de transporte coletivo neste tipo de território. Este trabalho gera contribuições para melhoria da operação deste serviço em uma cidade intermediária argentina, tendo como objetivo conhecer a distribuição espacial do mercado de transporte coletivo na área metropolitana de Mendoza. Se emprega uma metodologia quantitativa, através de técnicas estatísticas e cartográficas. Os resultados indicam que a maior parte do território apresenta uma situação de mercado equilibrada, o que faz com que durante o período de maior demanda exista uma necessidade de mobilidade que não é atendida, fato que é acentuado na periferia urbana. 


\section{Introducción}

En el pasado, las ciudades intermedias captaron poca atención de la academia, las políticas públicas y las agendas de desarrollo de los territorios nacionales. No obstante, han cumplido una importante función de integración territorial y mediación entre centros urbanos de gran envergadura y aquellos de menor tamaño, inclusive de áreas rurales. Asimismo, han adquirido un peso relativo significativo albergando el $36 \%$ de la población urbana mundial (Ciudades y Gobiernos Locales Unidos, CGLU, 2016), constituyéndose en territorios urbanos soporte de las dinámicas y actividades de otros de mayor tamaño, ya que presentan características más deseables para la sostenibilidad que estos últimos. Es decir, muchos de los impactos negativos producto de los acelerados procesos de urbanización de los grandes conglomerados, son aún incipientes en las ciudades intermedias, generando un potencial de gran valor para su desarrollo con sustentabilidad.

En la consideración de que el sistema de movilidad se configura como un componente clave del sistema urbano, se detecta que, en el caso de las ciudades intermedias, la adecuada planificación y gestión de la movilidad puede resultar uno de los caminos para alcanzar dicha sustentabilidad. Y uno de los elementos de este sistema, que por excelencia la favorecen y posibilitan, es el eficiente y equitativo funcionamiento del transporte colectivo, considerado un servicio de primera necesidad. Es por esta razón, que el estudio de este componente urbano y sus relaciones con el resto de la ciudad son de gran importancia para el abordaje de las ciudades intermedias.

En ese contexto, este trabajo pretende generar aportes para mejorar la eficiencia y equidad del sistema de transporte co- $^{-}$ lectivo en una ciudad intermedia argentina, teniendo como objetivo conocer las implicancias de la distribución espacial del mercado de este servicio en el Área Metropolitana de Mendoza. De esta manera, se segmenta el mercado en subáreas y se evalúa el equilibrio o desequilibrio en cada una de ellas, lo que posibilita identificar aquellos espacios geográficos con mayor necesidad de oferta.

Para ello, se emplea una metodología cuantitativa, particularmente a través de técnicas estadísticas y cartográficas, esta última, propia de la metodología del ordenamiento territorial. Inicialmente se identifican las características socioeconómicas del usuario promedio de este modo de transporte, luego, estas se localizan en las subáreas (distritos) que componen el área estudiada para conocer la distribución espacial de la demanda. Más adelante, se identifica la cobertura del servicio de transporte colectivo por subáreas, que representa a la oferta de este modo. Por último, se elabora un mapa a modo de síntesis con el fin de detectar la situación del mercado en cada subárea. Así, se segmenta el mercado con un criterio espacial 
y se identifican las áreas con exceso de oferta, de demanda o en equilibrio.

Los resultados indican que la mayoría de los distritos presentan una situación de mercado de equilibrio, lo cual implica que en los periodos de mayor concentración de la demanda pueda existir una necesidad de desplazamientos que no se satisface. Es decir, la oferta no puede servir a toda la demanda generada en ese periodo. Asimismo, se observa una concentración de la oferta en las áreas centrales dejando a algunas áreas periféricas con exceso de demanda permanente.

\section{El rol del transporte colectivo en ciudades intermedias}

Según consta en la bibliografía relacionada (Llop et al., 2019; Llop, 2008; Bolay \& Rabinovich, 2004; Bellet \& Llop, 2004b; Pulido, 2004), la definición de la ciudad intermedia, es al menos amplia y comprensiva de muchas y diversas realidades territoriales y, se vincula directamente al rol que cumple en el sistema urbano. Siguiendo a Llop et al. (2019), los criterios para definir la intermediación como función de estas urbes resultan territorialmente transversales, y por ello, pueden entenderse desde diversas dimensiones. En lo relativo a la movilidad, es de destacar que la ciudad intermedia adquiere una escala humana en términos que le permite relacionar hábitos de movilidad sostenible territarias 44 - mayor uso de transportes colectivos y de modos no contaminantes como la bicicleta y la caminata- con mezcla de usos del suelo, compacidad, proximidad y heterogeneidad, favoreciendo la mayor eficiencia en el uso del espacio urbano y el consumo racional de las energías. En palabras de Punsola (2014): "Estos centros urbanos cuentan con un mayor potencial para la sostenibilidad que las megalópolis" (p. 28), constituyéndose este en uno de los más grandes valores; además de su rol como intermediarias entre las distintas escalas y funciones territoriales, que favorecen los flujos de bienes, personas, información, servicios y demás, entre las grandes ciudades y el mundo rural. "Las relaciones que crean con las grandes urbes les permiten complementarse entre ciudades y funcionar como un sistema de ciudades" (Roig, 2014, p. 44).

En concordancia, Frick y RodríguezPose (2016), en un estudio comparativo de 114 países en el periodo que va de 1960 al 2010, en el cual evalúan la productividad económica, concluyen que a medida las ciudades se hacen más grandes, más crece en ellas la pobreza, la inestabilidad y las externalidades negativas como la contaminación, la congestión vehicular y los traslados más largos. Siendo esto cierto tanto en países industrializados como en países emergentes. Ferré et al. (2012), a su vez, postulan que la pobreza urbana es menor en pequeñas y medianas ciudades, que en ciudades grandes. Y Bolay (2020), afirma que las ciudades pequeñas y medianas tienen ventajas, ya que aún están 
a tiempo de adecuar sus infraestructuras y necesidades de servicios básicos para evitar las externalidades negativas.

Según Vuchic (1999, 2008), en las ciudades intermedias el transporte público colectivo da a la ciudad la posibilidad de desarrollarse a escala humana. Permite vivir la ciudad y acceder a todos sus servicios y posibilidades, a través del libre traslado sin necesidad de contar con un automóvil particular. Esto también resulta posible, cuando el transporte colectivo se integra con los modos sustentables como la bicicleta y la caminata, e incluso, cuando se coordina con el uso del transporte privado individual, en un marco de ordenamiento de los usos del suelo que favorezcan la accesibilidad. Particularmente, este servicio favorece a aquellos que por alguna razón no utilizan el automóvil, como son ancianos, niños, personas de menores ingresos o personas con alguna incapacidad para manejar. Por otra parte, algunos ejemplos interesantes de ciudades intermedias a escala humana con sistemas de transporte que favorecen la habitabilidad son, por excelencia: Portland en Estados Unidos, Vancouver en Canadá y Bonn en Alemania (Vuchic, 2008).

Lo anterior da cuenta que el sistema urbano y el sistema de movilidad son codependientes, interrelacionándose de manera dinámica y compleja (Rode \& Floater, 2014; Shamsul et al., 2013; Van Wee, 2013; Correa Díaz, 2010; Cervero, 2001), por lo que su planificación integrada se hace necesaria para alcanzar la sostenibilidad, cambiando el foco desde la oferta hacia la demanda y desde lo individual hacia lo colectivo. El objetivo es que la ciudad sea más accesible, acercar las actividades que permiten reproducir la vida cotidiana por medio de usos de suelo integrados que minimicen la necesidad de trasladarse. Luego, se busca optimizar el sistema de movilidad urbana, ya que una mejor accesibilidad y movilidad, son claves en el desarrollo a escala humana, lo cual implica una mejora en la calidad de vida.

La demanda de viajes - real y potencial- viene determinada o influenciada por los patrones de usos del suelo (Gakenheimer, 2006; Kelly, 1994; Cervero \& Seskin, 1995; Newman \& Kenworthy, 1996). Si la ciudad se expande espacialmente de manera no planificada, aumentan los requerimientos de viajes, generalmente con trayectos más extensos y con menores densidades promedio en su entorno, encareciendo el desarrollo de sistemas de transporte colectivo. En consecuencia, la ciudad se vuelve menos accesible y menos sostenible. La teoría tradicional de localización urbana (Alonso, 1964; Muth, 1969) sostiene que tanto las personas como las firmas, buscan localizaciones accesibles a fin de minimizar los costos de transporte y maximizar sus beneficios. Los lugares accesibles tienen ventajas en la localización, lo cual evidencia que los residentes de las periferias urbanas tienen menos accesibilidad, y territarias 44 147 
resulta en grandes desventajas para aquellos habitantes con pocas posibilidades de emplear un vehículo motorizado particular.

Se entiende entonces que, la ciudad intermedia por sus características territoriales intrínsecas, tiene gran potencial para alcanzar la accesibilidad y ser más habitable. Y que, en este contexto, es más fácil optimizar la movilidad urbana, que a la vez promueve el desarrollo con sostenibilidad (Maheshwari et al., 2016).

Por su parte, la escala humana se vincula estrechamente a las dimensiones físicas de la ciudad, principalmente a su superficie y cantidad de población. Según un estudio llevado adelante por la Cátedra Unesco de Ciudades Intermedias de la Universidad de Lleida, España (Bellet \& Llop, 2004b), la gran mayoría de las ciudades intermedias estudiadas concentran su población en un círculo con un radio medio de cuatro kilómetros, que en general comprenden el $70 \%$ del total de los habitantes. Esta distancia implica que la ciudad podría recorrerse a pie, de punta a punta, en menos de dos horas. Tal proximidad resulta una gran ventaja en términos de movilidad, considerando que en las grandes ciudades este radio en promedio supera los diez kilómetros, con requerimientos de transporte más complejos debido a la segregación socio espacial.

Respecto de la población, Roig territarias 44 (2014) afirma que las ciudades intermedias no superan el millón de habitantes.
Coincidentemente, según la definición de Ciudades y Gobiernos Locales Unidos (Llop et al., 2019), las ciudades intermedias son aquellas que tienen entre cincuenta mil y un millón de habitantes, franja que varía según el territorio, siendo ampliada en contextos espaciales como el asiático - China e India - y, reducida en Europa hacia los veinte mil habitantes. En América Latina, el rango de las ciudades intermedias se encuentra entre cincuenta mil y un millón de habitantes (Rodríguez, 2002).

Desde la perspectiva de la movilidad urbana resultan claves los criterios cuantitativos de definición de la ciudad intermedia, en tanto que la planificación del sistema de transporte, su red, recorridos y articulación, son modos que adquieren características diversas según la dimensión de la ciudad. "La distancia, por ejemplo, la opción de ir a pie, o de moverse entre hogar y trabajo en menos de media hora, son una ventaja competitiva de estas ciudades frente al problema de movilidad de las grandes urbes" (Llop, 2014 , p. 1). Asimismo, las funcionalidades y dinámicas del territorio urbano, en cuanto intermediario entre centros urbanos mayores y áreas rurales, determinan la localización y distribución de la oferta y la demanda - real y potencial- del transporte. En ese sentido, es relevante analizar este sistema, componente fundamental del sistema urbano, previendo ambos criterios para su planificación. 
Además, junto a estos criterios se considera uno orientado exclusivamente al transporte colectivo que impacta en toda la estructura y dinámica urbana. Este criterio da pautas de sostenibilidad sobre la estructura física de la red de transporte, según sea la dimensión del territorio urbano en términos de su población. Concretamente, estima que para una ciudad menor a trescientos mil habitantes, los recorridos radiales son adecuados en cuanto vinculan a toda la población con el núcleo central de actividades. Para urbanizaciones de mayor tamaño resulta más sostenible incorporar recorridos diametrales, tangenciales y circulares o semicirculares (Molinero Molinero \& Sánchez Arrellano, 2005). Estos dos últimos tipos de rutas no atraviesan el centro de mayor actividad, sino que responden a necesidades de traslados de otras áreas o centros de menor envergadura, favoreciendo el desarrollo más equilibrado del territorio urbano.

Ahora bien, más allá que desde una perspectiva teórica las ciudades intermedias se configuren como territorios con potencial de sustentabilidad, se detecta que muchas de ellas no se desarrollan a escala humana fagocitando las características intrínsecas favorables a la accesibilidad y sostenibilidad. Al respecto, López y González (2019), refiriéndose a las ciudades medias de León y Castilla en España, afirman que "en la mayoría de estos núcleos intermedios el crecimiento urbano ha sido difuso e irregular, generando procesos de expansión discontinuos" (p. 3), desencadenando altos índices de contaminación, congestión vehicular y menor seguridad en los viajes. Lo cual dificulta la accesibilidad y movilidad. Por su parte, Martner (1996) describe una situación similar para ciudades de porte medio latinoamericanas, en particular, se refiere a ciudades mexicanas en las que se detecta una notable intensificación de la movilidad de los habitantes que requieren viajar diariamente fuera de sus comunidades para satisfacer sus necesidades socioeconómicas (Martner, 2015). En consonancia, Flora (2001) sostiene que:

Para promover la sustentabilidad social, especialmente en la mejora del acceso físico a los trabajos, la infraestructura y los sistemas deben proporcionar movilidad a las personas, un problema típico en Latinoamérica, donde la población de menores ingresos vive fuera del centro de la ciudad que es donde está la mayoría de los trabajos. Por lo tanto, es necesario reducir las barreras al sector informal, contrariamente a la práctica usual de cerrarle el paso. Cualquier discriminación de género, aunque con frecuencia inconsciente, también debe ser eliminada. Las mujeres, casi siempre la espina dorsal de la familia y contribuyentes al ingreso familiar, frecuentemente no tienen acceso a los servicios que ellas necesitan. En términos de planificación del uso de suelo, en la práctica, nuestros sistemas han segregado a la población más 
pobre, hasta el punto que pierde la accesibilidad (p. 362).

Argentina no está exenta de estos procesos, mientras que sus ciudades intermedias han sufrido en los últimos 30 años un crecimiento, tanto espacial como poblacional, sin interrupciones, siguiendo la lógica del mercado inmobiliario (C3T, 2016; Anapolsky \& Pereyra, 2012). Esta ausencia de planificación se pone de manifiesto en la aparición acelerada de externalidades negativas, que perjudican las ventajas de la accesibilidad y las posibilidades de un desarrollo sostenible.

\section{Área de estudio}

El lugar de estudio es el Área Metropolitana de Mendoza, localizada en el oasis norte de la provincia de Mendoza, Argentina, que se presenta como el principal conglomerado urbano del oeste argentino en la medida que concentra las actividades económicas más dinámicas de la región, siendo un nodo de importancia nacional e internacional en el corredor bioceánico. Dicha área abarca el territorio de 6 jurisdicciones municipales diferentes $\mathrm{y}$, contiene una población estimada de casi 1200000 habitantes para el 2016 (Gobierno de Mendoza, 2018).

De acuerdo a sus dimensiones, este centro urbano excede el tamaño de una ciudad intermedia. Contiene una población de más de un millón de habitantes que se expande en un radio de más de cuatro kilómetros - aproximadamente de siete kilómetros-, dando cuenta que supera la escala humana que favorece a los territorios sostenibles. A su vez, se comenzaron a detectar en las últimas tres décadas, los efectos adversos de los procesos de urbanización acelerados y espontáneos. Una ciudad expandida espacialmente, con espacios intersticiales vacíos, crecimiento desordenado que genera fragmentación espacial, segmentación y marginación social e impactos ambientales negativos. Todo ello, evidenciando una ciudad que tendencialmente no se desarrolla con sostenibilidad, aunque con posibilidades de mitigar o detener estos procesos negativos, aún no completamente instalados. Más allá de estas características cuantitativas, este centro urbano cumple una marcada función de intermediación entre espacios urbanos de mayor envergadura, como la ciudad de Buenos Aires, Santiago de Chile y San Pablo; y los nodos de menor tamaño, inclusive las áreas rurales. Dicho de otra manera, el Área Metropolitana de Mendoza, si bien se constituye con una estructura de ciudad grande, opera con una dinámica de ciudad intermedia, lo que presenta un desafío para la planificación y la gestión del modelo de movilidad.

Este desafío cuenta con dos potencialidades. Por un lado, la existencia de una ley marco de ordenamiento territorial que favorece los procesos que conducen a una mayor sostenibilidad urbana. Por otro, la existencia de una política de movilidad 
y transporte con larga trayectoria y con competencia jurisdiccional provincial, permitiendo la coordinación de los municipios que integran el área urbana.

Respecto al modelo de movilidad imperante se detecta, no obstante, una gran limitación, la mayoría de los recorridos de la red de transporte colectivo son radiales $(60 \%)$, un porcentaje menor es diametral $(25 \%)$ y los restantes son circulares o tangenciales. En otras palabras, el servicio opera como en una ciudad de menores dimensiones, por lo que se estima que esta característica resultará perjudicial en el adecuado comportamiento del sistema y de su mercado.

\section{Abordaje teórico}

Se toma como punto de partida la concepción y relación sistémica de la movilidad y del territorio urbano. En palabras de Correa Díaz (2010),

[...] los servicios de transporte público operan de manera sistémica, así como lo hace todo aquello que se mueve en la ciudad. Toda intervención que se haga respecto a uno de los modos que la gente usa para movilizarse afecta inevitablemente al resto (p. 133).

A lo que Velázquez (2015) adiciona que, "la movilidad es afectada por la planificación urbanística, así como por la estructura organizacional de la ciudad" (p. 51). Esta relación resulta más fluida y equilibrada en ciudades intermedias, generando mayores beneficios en relación a la sostenibilidad.

De esta forma, se entiende que el sistema de transporte colectivo es un componente fundamental en el sistema de movilidad y en el sistema urbano. La movilidad que busca ser sostenible, prioriza al transporte colectivo como el modo que por excelencia garantiza el desplazamiento de todos los habitantes de un territorio (Santos \& De las Rivas, 2008), el que genera menores emisiones contaminantes en conjunto y optimiza la utilización del espacio urbano. El presente estudio pone este servicio en el centro de la escena para realizar un aporte sobre el conocimiento de su comportamiento.

En este marco, se aborda el análisis desde la perspectiva de la economía del transporte, asumiendo la existencia de un mercado de transporte colectivo que opera a través de las fuerzas de la oferta y la demanda. Estas funciones tienen particularidades que necesariamente deben considerarse para la planificación del servicio en el territorio.

Por el lado de la demanda, se observa que es derivada, es decir, el traslado o desplazamiento no se demanda como un fin en sí mismo, sino que usualmente su necesidad se deriva de otras actividades (Islas Rivera et al., 2002) que se realizan en diversas localizaciones del territorio.

La movilidad es una práctica social de desplazamiento entre lugares con el fin de concretar actividades cotidianas. Involucra territarias 44 
el desplazamiento de las personas y sus bienes, y conjuga deseos y/o necesidades de viaje (o requerimientos de movilidad) y capacidades objetivas y subjetivas de satisfacerlos [...] (Gutiérrez, 2012, p. 58).

Esto evidencia una relación recíproca entre el transporte colectivo y los usos del suelo. Las áreas residenciales y laborales, los equipamientos de salud, educación y recreación, se constituyen como polos atractores y generadores de viajes.

A su vez, la cantidad demandada de viajes en transporte colectivo, viene determinada por diversas variables que la afectan. Entre ellas, la tarifa del servicio, las características socioeconómicas de los usuarios, el costo de usar servicios sustitutos, la calidad y accesibilidad del servicio - vinculada a la cobertura y otras variables-, el tiempo de viaje, la cultura y costumbres de cada sociedad, y, la política de transporte - grado y modo de intervención del Estado en la regulación de la actividad-(de Rus et al., 2003). Generalmente, en los estudios de transporte se consideran los usuarios efectivos del servicio, dejando de lado aquellos usuarios potenciales, que por diversos motivos —inaccesibilidad física o económica-, prefieren otros modos de transporte. En esta diferenciación entran en juego las capacidades objetivas y subjetivas para satisfacer la demanda que menciona $\mathrm{Gu}^{-}$ tiérrez (2012), y que desde la economía del transporte, se conceptualiza como demanda real y demanda potencial.
Por el lado de la oferta, existen dos funciones de producción diferenciadas, una de ellas es la prestación del servicio y la otra es la producción de infraestructuras (de Rus et al., 2003). Ambas, quedan determinadas, entre otras variables, por la política pública que define el modelo de movilidad existente en un territorio. Haciendo foco en la prestación del servicio, las variables que la explican son la tarifa del servicio, los costos de los factores productivos - parque móvil, personal de conducción, combustibles, recursos naturales, suelo urbano ocupado-y la tecnología de producción. En conjunto, estas generan un servicio (output) que puede medirse en diversas maneras: cantidad de viajes, pasajeros transportados $\mathrm{y}$ cobertura del servicio.

Las funciones de oferta y demanda se relacionan de manera sistémica, lo que acontece en alguno de sus componentes indefectiblemente afecta al resto. Por ello, no puede afirmarse que la demanda (nivel, localización) determine de manera unilateral a la oferta o viceversa. En ocasiones, donde se localiza la demanda aparece (se exige) la oferta del servicio; también ocurre que donde se localiza la oferta se genera la demanda. El primer caso se da, sobre todo, en áreas periféricas y de expansión del territorio urbano donde se localiza la demanda y requiriere de la extensión de la oferta; en general, esto acontece de manera desordenada y espontánea siguiendo las reglas de juego del mercado inmobiliario. El segundo 
caso, se vincula más a la planificación de la movilidad y el territorio, en la medida que la expansión de la cobertura del servicio, hacia áreas estratégicas de crecimiento urbano, genera como consecuencia la atracción de la demanda. Esta relación de características sistémicas da cuenta, asimismo, del estrecho vínculo entre el sistema de transporte colectivo y los usos del suelo en el territorio.

Esta relación sistémica entre la oferta y la demanda de transporte genera un requerimiento distintivo de este mercado, en tanto es necesario un adecuado ajuste entre ambas funciones en el tiempo y en el espacio, para evitar grandes faltantes o excedentes en determinados horarios o áreas. Esto se vincula al atributo de no almacenabilidad del servicio que debe consumirse en el momento que se presta, porque de otra manera se pierde. Dado que la demanda no se distribuye de manera uniforme en el tiempo - existen horas pico y horas valle-, o en el espacio -áreas de mayor tráfico o densidad y áreas con menor necesidad de atracción del servicio-, se presenta, entonces, un desafío al momento de planificar el servicio para coordinar ambas funciones y sus variabilidades. Este desafío puede afrontarse en principio coordinando los usos del suelo con el sistema de transporte, como también utilizando la tecnología y el tamaño de vehículos adecuados para cada momento y lugar.

En este trabajo se hará foco en la distribución espacial de la demanda y la capacidad de la oferta para satisfacerla, considerando que en el área de estudio existe una estructura de recorridos principalmente radial, que concentra la cobertura en las áreas cercanas al núcleo central de actividades.

\section{Abordaje metodológico}

Para llevar adelante este análisis se emplea una metodología cuantitativa a través de técnicas, herramientas estadísticas y cartografía. Por un lado, se hace uso del modelo secuencial de demanda de transporte, técnica estadística típicamente utilizada para estimar las características socioeconómicas de las personas que demandan este servicio. Así mismo, se lleva adelante un análisis espacial a través de cartografía, una herramienta perteneciente a la metodología del ordenamiento territorial, que permite relacionar variables en un territorio por medio del uso de sistemas de información geográfica.

Estas técnicas se emplean de la siguiente manera. Por el lado de la demanda, como primer paso, se realizan las regresiones del modelo secuencial de demanda de transporte, específicamente mediante la etapa de selección modal, estableciendo así el perfil del viajero promedio del transporte colectivo. Para esta etapa se utiliza el modelo econométrico logit binomial que se estima con el programa estadístico Stata y con información proveniente de la Encuesta de Origen y Destino (2010) realizada para el área en 
estudio. Después, estos datos, relativos a las características del demandante promedio del servicio, se localizan espacialmente a través un sistema de información geográfico. Dicha localización se hace por distritos y permite evaluar la distribución en el territorio de la demanda de transporte colectivo. Se detectan así las áreas (distritos) de mayor demanda real de transporte colectivo, quedando la demanda total del servicio segmentada por el espacio físico en el que se localiza. Para incluir en el estudio no solamente a la demanda real sino también la potencial, se considera una variable adicional, la población que presenta al menos un indicador de necesidades básicas insatisfechas. Se asume que este grupo de habitantes del territorio urbano es demandante potencial en tanto que desearía emplear el servicio de transporte colectivo, pero por inaccesibilidad física o económica no lo hace. Esta variable también se localiza espacialmente por distritos, lo que permite conocer la distribución en el territorio de las personas con menores niveles de ingreso que podrían utilizar el transporte colectivo pero no lo hacen, es decir, representando a la demanda potencial.

Por el lado de la oferta, se emplea directamente la técnica cartográfica para conocer la cobertura del servicio por distrito. Para ello, se realiza un buffer de 500 metros ( 5 cuadras aproximadamente) a cada recorrido de transporte colectivo, definiendo así el porcentaje de superficie del distrito que cubre cada uno de ellos.
Esta estimación supone que la demanda se satisface a esa distancia como máximo y, que las personas que se localizan a mayor lejanía emplean otro modo de transporte. Asimismo, se asume que la población está distribuida equitativamente en el territorio, así que por ejemplo, si un distrito se encuentra cubierto en un $\mathbf{5 5 \%}$ de su superficie con el servicio de transporte colectivo, se infiere que el $55 \%$ de su población tiene acceso a este. Dicho procedimiento permite conocer cuáles son los distritos de mayor cobertura del servicio, y a la vez, representa su oferta.

Finalmente, mediante la cartografía síntesis se contrasta la oferta y la demanda en cada distrito, detectando la situación del mercado en cada uno de ellos, la cual puede representar tres situaciones: equilibrio, exceso de demanda o exceso de oferta.

En este análisis se supone que la demanda es en promedio, es decir, no se considera su variación en el tiempo, sino que se hace foco solamente en la dimensión espacial. De esta manera, resultan deseables las situaciones de exceso de oferta en la medida que permitirían alcanzar un equilibrio en los momentos de mayor demanda.

\section{Estimación de la demanda real}

El modelo empleado usualmente para estimar la demanda real de transporte, recibe el nombre de modelo de planeación del transporte o modelo de cuatro fases. 
Como su nombre lo indica, se compone de cuatro etapas que pueden modelarse de manera independiente así:

a. Generación de viajes: ¿̨cuántos viajes se realizan y dónde se generan?

b. Distribución de viajes: ¿cuál será el destino de cada viaje?

c. Selección modal: ¡qué modo de transporte se utiliza?

d. Asignación de ruta: ¿qué ruta concreta entre el origen y el destino se elige?

Para estimar las características de la persona promedio que demanda transporte colectivo se requiere desarrollar la fase de selección modal, que permite determinar los factores que aumentan la probabilidad que una persona elija como modo de transporte a aquel que es colectivo. Estos factores refieren a las características socioeconómicas del individuo y al atractivo relativo del transporte colectivo (Ortúzar \& Willumsen, 2011).

Con este fin, se emplean modelos de elección discreta que se sustentan en el enfoque de preferencias declaradas, obtenidas a partir de encuestas realizadas a los viajeros (Moreno Quintero, 2011). Dado que la elección del viajero es una declaración de sus preferencias, el modelo teórico adecuado es la teoría de la utilidad que a través de una función matemática representa las preferencias de los viajeros del sistema, suponiendo que estos buscan maximizar su utilidad. Los elementos que componen esta función son: el conjunto de modos alternativos de transporte -ómnibus, auto particular, bicicleta-, los atributos de cada modo de transporte - tiempo de viaje, costo-y, el conjunto de características del individuo que realiza la elección —edad, sexo, ingreso-.

La función de utilidad no tiene una forma única, sino que puede ser cualquier función matemática que dé cuenta del orden de preferencias de los viajeros. Se hace uso de la teoría de elección discreta de alternativas, que postula que se selecciona la opción que maximiza la utilidad aleatoria y amplía el concepto de función de utilidad, incorporando un término de error para "representar todos los factores no conocidos por el analista y que influyen en la decisión del viajero" (Moreno Quintero, 2011, p. 16). En los modelos anidados en esta teoría, se calcula la probabilidad de elegir una opción (modo) de transporte a partir de sus características socioeconómicas y del atractivo relativo de dicha alternativa.

Para desarrollar empíricamente la teoría de la utilidad aleatoria en el caso de estudio, se aplica un modelo de regresión logística binomial (logit binario) que considera que, para los individuos solo hay dos elecciones posibles. En otras palabras, se determina la probabilidad de que una persona opte por transporte colectivo para realizar un viaje, en vez de la otra alternativa que es transporte individual.

La variable explicada $Y$ es una variable dicotómica que solo considera dos 
alternativas: transporte colectivo o individual. Toma los siguientes valores:

$\mathrm{l}=$ transporte colectivo (ómnibus y trolebús). Es la categoría de referencia.

$0=$ transporte individual (automóvil particular, moto, bicicleta, taxi, remis). delo es:

La especificación completa del mo-

$\mathrm{Y}_{\mathrm{i}}^{*}=\beta_{1} \mathrm{X}_{1 \mathrm{i}}+\beta_{2} \mathrm{X}_{2 \mathrm{i}}+\beta_{3} \mathrm{X}_{3 \mathrm{i}}+\ldots+\varepsilon_{\mathrm{i}}$ $Y_{i}=1$ si $Y_{i}^{*}>0, Y_{i}=0$ si $Y_{i}^{*} \leq 0$

$\operatorname{Prob}\left(Y_{i}^{*}=1\right)=F\left(\beta_{0}+\beta_{1} X_{1 i}+\beta_{2} X_{2 i}\right.$ $\left.+\ldots+\beta_{\mathrm{n}} \mathrm{X}_{\mathrm{ni}}\right)$

Donde:

$\mathrm{Y}_{\mathrm{i}}=1$ si el individuo $\mathrm{i}-$ ésimo usa el transporte colectivo, $\mathrm{Y}_{\mathrm{i}}=0$ si usa el transporte individual.

$\mathrm{F}=$ función de distribución acumulada

$\mathrm{X}_{\mathrm{i}}=$ variables explicativas

$\beta_{\mathrm{i}}=$ parámetros

La elección del modo de transporte depende de un vector $\mathrm{X}_{\mathrm{i}}$ de dimensión $\mathrm{n}$, compuesto por variables que caracterizan personalmente al usuario (edad, género, nivel de educación, nivel de ingresos), por variables acerca de las características del modo de transporte (cantidad de viajes) territarios 44 y por variables relativas a las características del hogar (cantidad de personas que componen el hogar, cantidad de vehículos que poseen). La constante $\beta_{0}$ se interpreta como la influencia neta de todos los factores no observables o no explícitamente incluidos, ya sea del individuo o de la alternativa de transporte, que afectan la elección del modo de transporte.

$\mathrm{La}$ información que proporciona la estimación total del modelo, permite determinar la probabilidad de que un individuo sea usuario de transporte colectivo dadas ciertas características y en un momento determinado.

El modelo de regresión logística binomial en el caso de estudio se expresa de la siguiente manera:

$\operatorname{Prob}\left(\mathrm{Y}_{\mathrm{i}}^{*}=\mathrm{l}\right)=\mathrm{F}\left(\beta_{0}+\beta_{1}\right.$ edad $+\beta_{2}$ género $+\beta_{3}$ nivel de estudios $+\beta_{4}$ ingreso per cápita $+\beta_{5}$ cantidad de viajes $+\beta_{6}$ número de personas $+\beta_{7}$ cantidad de vehículos)

Las variables independientes o explicativas del modelo, que intentan caracterizar al usuario habitual del transporte colectivo, son las siguientes:

- Características personales: edad (variable dicotómica, toma el valor 0 si el usuario tiene entre 15 y 64 años y, el valor 1 si el usuario tiene 65 años o más), género (variable dicotómica, toma valor 0 si el usuario es hombre y el valor 1 si el usuario es mujer), nivel de estudios (variable dicotómica, toma valor 0 si el usuario tiene alguno de

MARÍA EMILIA GARCÍA SCHILARDI 
los siguientes niveles educativos: ninguno, primario incompleto, primario completo, secundario incompleto, secundario completo, terciario incompleto; toma el valor 1 si el usuario tiene alguno de los siguientes niveles educativos: universitario incompleto, terciario completo, universitario completo, posgrado), ingreso per cápita (variable que mide el ingreso per cápita de los individuos).

- Variables que caracterizan a la modalidad de transporte: cantidad de viajes (expresa la cantidad de viajes diarios que realiza el usuario, toma valores entre 0 y 16, siendo 2 el valor más frecuente; $60,48 \%$ de la muestra).

- Variables relacionadas con características del hogar: número de personas (expresa la cantidad de personas que viven en el hogar, toma valores entre 1 y 12), cantidad de vehículos (variable que expresa la cantidad de automóviles de los que dispone un hogar, toma valores entre 0 y 5 ).

El modelo elegido para explicar el comportamiento del usuario promedio de transporte colectivo, se seleccionó de un grupo de modelos similares, en función de la significatividad estadística de las variables explicativas y de la utilidad para interpretar los resultados en cartografía.

Este modelo se calibró sobre la base de datos desagregados de la Encuesta Origen y Destino (2010) y tiene un total de 13110 observaciones.
Los valores de los coeficientes señalan la dirección de la relación entre la variable independiente y la variable explicada.

Los resultados de la estimación se reflejan en la tabla 1. En la primera columna se observan los valores de los coeficientes $\beta_{\mathrm{jk}}$ estimados, en la segunda se reportan los errores estándar de la estimación de cada coeficiente, en la tercera se indican los valores estadísticos de significatividad individual de los coeficientes ${ }^{1}$ y en la cuarta se evalúa la hipótesis nula de que cada uno de los coeficientes sea igual a cero.

El valor del logaritmo de la función de verosimilitud de la estimación (log likelihood) indica un buen ajuste global del modelo. ${ }^{2}$ Este indicador se complementa con la probabilidad de un chi $^{2}$ la cual es suficientemente pequeña (igual a $0,0000)$ para rechazar la hipótesis nula, por lo que las variables explicativas tienen un efecto significativo en conjunto sobre el modelo. Asimismo, las variables explicativas individualmente tienen todas significancia estadística.

Por el signo negativo del coeficiente de la variable edad, se detecta que para el grupo de población de entre 15 y 64 años es más probable viajar en transporte colectivo que individual. En cambio, para el grupo poblacional de más de 65 años es más probable que viajen en vehículo particular. Respecto de la variable género, se observa que es más probable que las mujeres usen el transporte colectivo. El coeficiente de la variable nivel de estudios da cuenta de que si el nivel es básico, es
${ }^{1}$ El estadístico z es un pseudo estadistico t, debido a que solo se conoce su distribución asintótica, la cual está dada por la distribución normal estándar y no por la distribución t-student como en los modelos lineales bajo el supuesto de normalidad.

${ }^{2}$ Valores absolutos bajos del ratio log likelihood, significan que el resultado observado es menos probable que ocurra de acuerdo con la hipótesis nula, en comparación a la hipótesis alternativa. Es decir, valores altos del estadistico implican que el resultado observado es más probable que ocurra según la hipótesis nula que la hipótesis alternativa, por lo que la hipótesis nula no puede rechazarse.

tersitarios 44

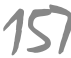


Tabla 1. Estimación a través de un modelo logit binomial

\begin{tabular}{|c|c|c|c|c|c|c|}
\hline & & & & & & \\
\hline & & & & Núm & ro observacio & es $=13110$ \\
\hline & & & & & LR $\operatorname{chi} 2=12$ & 1,92 \\
\hline & & & & & rob $>$ chi $2=$ &, 0000 \\
\hline Log likelihood = - & 64,4101 & & & & Pseudo $\mathrm{R} 2=\mathrm{C}$ &, 0742 \\
\hline Transporte colectivo & Coeficiente & Error estándar & $\mathbf{z}$ & $P>1 z 1$ & $95 \%$ interval & de confianza \\
\hline Edad & $-0,451927$ & 0,0576754 & $-7,84$ & 0,000 & $-0,5649688$ & $-0,3388853$ \\
\hline Género & 0,5091844 & 0,0381121 & 13,36 & 0,000 & 0,4344861 & 0,5838827 \\
\hline Nivel de estudio & $-0,5302097$ & 0,0652668 & $-8,12$ & 0,000 & $-0,6581303$ & $-0,402289$ \\
\hline Ingreso per cápita & $-0,0002956$ & 0,000038 & $-7,77$ & 0,000 & $-0,0003701$ & $-0,000221$ \\
\hline Cantidad de viajes & 0,1976093 & 0,0156691 & 12,61 & 0,000 & 0,1668984 & 0,2283202 \\
\hline Número de personas & 0,0632827 & 0,0145074 & 4,36 & 0,000 & 0,0348487 & 0,0917168 \\
\hline Cantidad de vehículos & $-0,6142069$ & 0,0269807 & $-22,76$ & 0,000 & $-0,667088$ & $-0,5613258$ \\
\hline Constante & 0,6272311 & 0,0549894 & 11,41 & 0,000 & 0,5194538 & 0,7350084 \\
\hline
\end{tabular}

Fuente: elaboración propia con datos de la Encuesta Origen y Destino (2010).

más probable elegir el transporte colectivo como modo de transporte, mientras que si el nivel es superior se elige con más probabilidad el vehículo individual. En referencia al variable ingreso per cápita, se observa que mientras mayor es el nivel de ingreso es más probable elegir transporte particular, esto es, que el transporte colectivo es más probable que lo elijan quienes tienen menor nivel de ingresos. El coeficiente de la variable cantidad de viajes muestra que mientras estos sean más numerosos, es más probable el uso del transporte colectivo. También se observa que mientras más sean los miembros de un hogar, se utiliza en mayor medida el transporte colectivo.
Esta variable presenta signo contrario al esperado en tanto que a mayor cantidad de personas que viajan en el hogar, cabría suponer una preferencia por el vehículo particular dado que el costo marginal del viaje en estos modos es nulo al transportar más personas en el mismo vehículo. No obstante, una explicación para el caso estudiado es que las familias más numerosas sean aquellas de menores recursos y no dispongan de vehículo particular. Finalmente, la variable cantidad de vehículos tiene un coeficiente estimado de signo negativo que implica que mientras se disponga de más vehículos en el hogar, es menos probable utilizar el transporte colectivo. 
Este mismo tipo de análisis, con algunas diferencias metodológicas, se realizó para las Encuestas de Origen y Destino de 1998 y el 2005 (Ballabio, 2004; Reta, 2007; Lara, 2003), proveyendo resultados coincidentes para las estimaciones de los coeficientes.

Al considerar las variables explicativas correspondientes a las características personales, se definió el perfil del usuario promedio del transporte colectivo, que presenta los siguientes atributos: personas con edad entre 15 y 64 años, mujeres, con nivel de estudio básico e ingresos bajos. Estos factores son acumulativos, implicando que mientras más de ellos se encuentren presentes en una persona, mayor es la probabilidad de que esta elija el transporte colectivo.

Por último, es conveniente realizar una aclaración. La consideración de que a menor ingreso es más probable elegir el transporte colectivo, no es del todo cierta. Los grupos de niveles de ingreso muy bajos no acceden a este modo de transporte porque les resulta inasequible. En el caso estudiado, existe una limitación metodológica y se los incluye como demandantes reales del servicio cuando en realidad son demandantes potenciales.

\section{Distribución en el territorio de la demanda}

Una vez definidas las características del perfil promedio de los usuarios de transporte colectivo, se localizan en el territorio del Área Metropolitana de Mendoza de la siguiente manera:

- Edad: se distinguen los distritos con mayor porcentaje de personas con edad entre 15 y 65 años (más del $50 \%$ ), de aquellos con un porcentaje menor.

- Género: se distinguen los distritos con mayor porcentaje de mujeres (más del $50 \%$ ), de aquellos con un porcentaje menor.

- Nivel de estudios: se distinguen los distritos con mayor porcentaje de personas con nivel de estudio básico (más del $50 \%$ ), de aquellos con un porcentaje menor.

- Ingreso per cápita: como variable aproximada dicotómica se considera que los individuos con niveles bajos de ingresos per cápita, vienen representados por los individuos con presencia de al menos un indicador de necesidades básicas insatisfechas; $\mathrm{y}$ los individuos con niveles medios y altos de ingresos per cápita, vienen representados por los individuos sin ningún indicador de necesidades básicas insatisfechas. Cartográficamente, esta variable dicotómica se visualiza distinguiendo los distritos con mayor porcentaje (más del 10\%) de hogares con presencia de al menos un indicador de necesidades básicas insatisfechas, de aquellos con un porcentaje 
menor. Esta variable da cuenta de los distritos con mayor demanda potencial de transporte.

Estos cuatro mapas se superponen obteniendo un mapa síntesis (figura 1) en el cual es posible determinar, para cada distrito, la presencia de una, dos, tres o cuatro características o condiciones del usuario promedio. Se conoce así, la distribución espacial de aquellas personas que demandan, real y potencialmente, transporte colectivo y, en consecuencia, se detectan las áreas que requieren más servicio.

En este mapa síntesis (figura l) se detectan tres situaciones posibles: distritos en donde se cumplen las 4 características del usuario promedio de transporte colectivo, distritos en donde se cumplen 3 características o, distritos en donde se cumplen solo 2 condiciones. En todos los distritos se presenta al menos una de las condiciones que caracteriza al usuario promedio de transporte colectivo. Esto es así ya que en todos los distritos del territorio urbano existe mayoría de población entre los 15 y 64 años, siendo esta una de las características que define a quienes demandan con mayor intensidad el servicio de transporte colectivo.

Se observa que en 5 distritos ubicados en la periferia de las áreas norte, este y oeste, se cumplen las 4 condiciones. Estos territorios son las áreas de mayor demanda de este servicio. En 48 de los 60 distritos urbanos, se presentan
3 características. A saber, en la mayoría $(80 \%)$ del territorio que comprende el Área Metropolitana de Mendoza se encuentran 3 características que determinan al perfil del usuario promedio de transporte colectivo. $\mathrm{Y}$, finalmente, en 7 distritos urbanos se encuentran solo dos características del usuario promedio de transporte colectivo. Es decir, serían las zonas en donde se elige con menor probabilidad el uso de transporte colectivo, las cuales se concentran en el departamento de capital, y en la periferia hacia el sur y este del Área Metropolitana.

En síntesis, la demanda de transporte colectivo se distribuye en todo el territorio metropolitano. Existen áreas con mayor requerimiento de este servicio que se localizan en la periferia norte, este y oeste. Algunos distritos cercanos al área central y periféricos en el este y sur del territorio urbano, presentan menos demanda del servicio.

\section{Distribución en el territorio de la oferta}

A continuación, se analiza la oferta del servicio a través de su cobertura. Esto permite evaluar si el servicio llega a quienes más lo demandan. Para ello, se estima un área de influencia de 500 metros ( 5 cuadras aproximadamente) para los recorridos de cada grupo y, se determina así la cobertura de toda la red a escala distrital. Debido a que las paradas se encuentran distribuidas cada 5 cuadras, 
Figura 1. Distribución espacial de las características del usuario promedio de transporte colectivo AMM

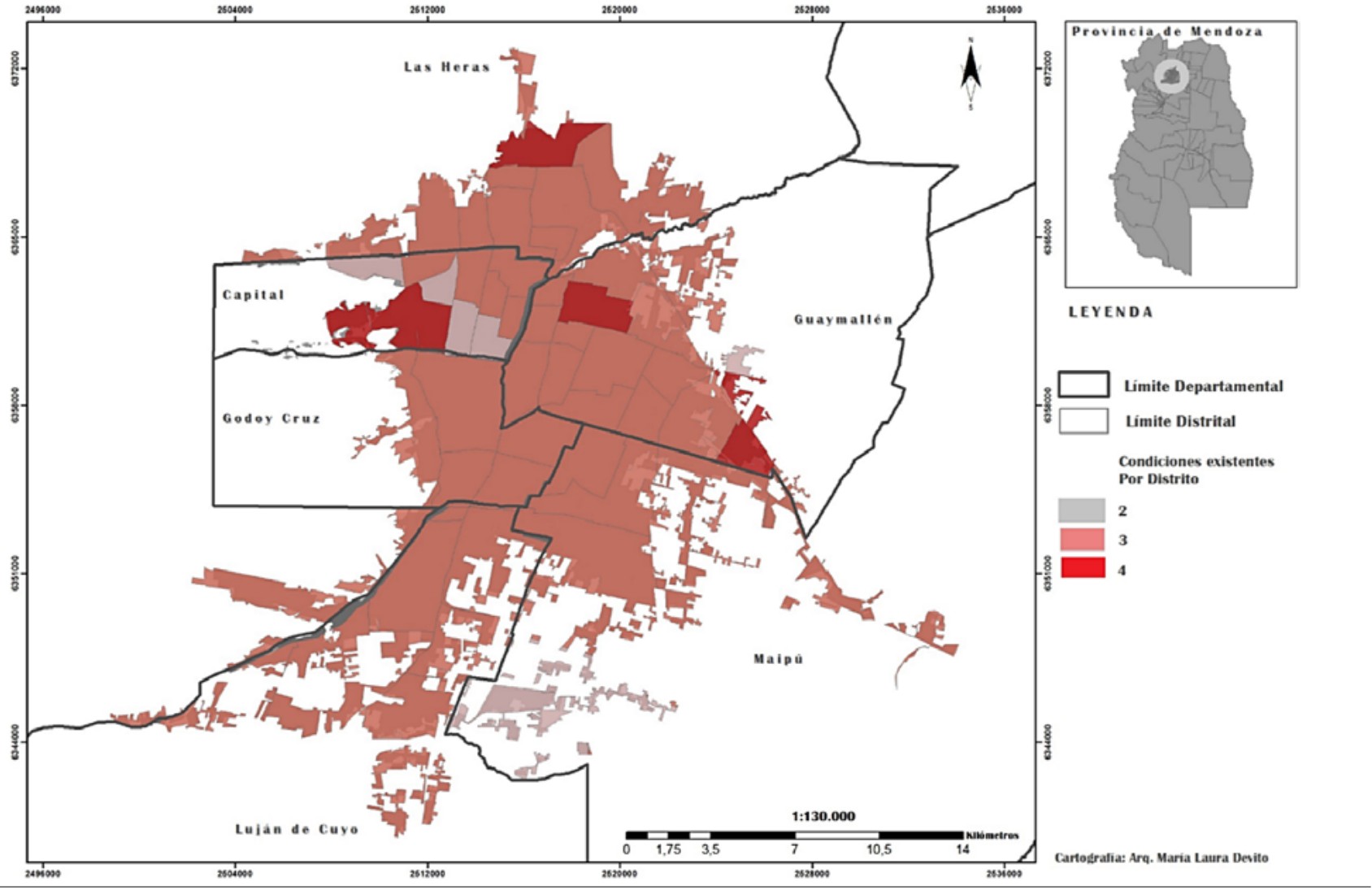

Fuente: DeIE, Censo Nacional de Población, Hogares y Viviendas (2010).

resulta equivalente realizar un buffer de cada parada a realizar y un buffer del trayecto del recorrido.

El Área Metropolitana de Mendoza (AMM), en general, tiene una buena cobertura de su servicio de transporte colectivo - el $88 \%$ de la superficie urbana está cubierta-. Se observa que el $47 \%$ de los distritos tiene una cobertura suficiente, el $35 \%$ una cobertura regular y solo el $18 \%$ una cobertura deficiente. Estos últimos, localizados en las áreas periféricas del espacio urbano. De este modo, es posible determinar, que existe una concentración del transporte público en el microcentro y disminuye la cobertura hacia la periferia, siguiendo el patrón de predominancia de recorridos radiales respecto de aquellos diametrales o circulares (figura 2). 
Figura 2. Cobertura del servicio de transporte colectivo en el AMM

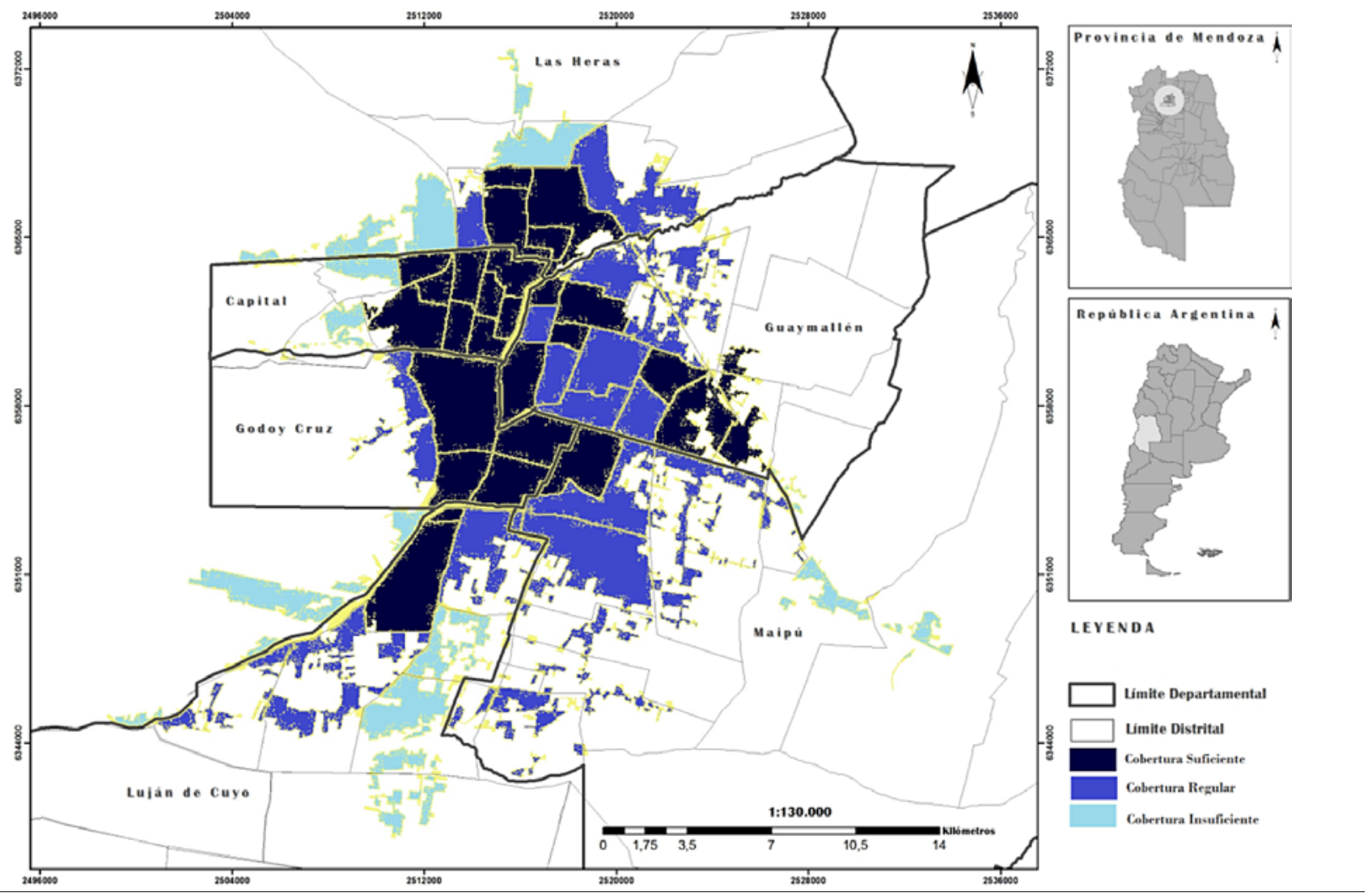

Fuente: Secretaría de Transporte de Mendoza (2017).

Estas áreas periféricas requieren ser priorizadas en el ordenamiento del sistema de transporte colectivo, para que el servicio satisfaga óptimamente a todos los distritos que componen el espacio metropolitano.

Es oportuno aclarar que el análisis se realizó en función del sistema de reco-

territarias 44 162 A partir del mes de enero del 2019 se implementa, en el territorio analizado, una reestructuración del servicio de transporte colectivo, que plantea entre sus objetivos jerarquizar los recorridos para descomprimir el núcleo central y expandir la cobertura de la red. Este cambio podría traducirse en mejoras de la oferta del servicio en general y, en particular, en los territorios más periféricos. No obstante, el análisis de este nuevo sistema 
de recorridos, resulta aún prematuro en tanto la red sigue sufriendo ajustes y modificaciones en función de las demandas que se van generando.

\section{Resultados sobre la situación del mercado de transporte colectivo}

Se detecta que la distribución espacial de la demanda es relativamente uniforme en todo el territorio estudiado, aunque la de mayor intensidad se localiza en distritos periféricos. A su vez, si bien la cobertura es suficiente, en promedio $88 \%$ de la superficie urbana total, se concentra en los distritos centrales, dejando a los periféricos con una oferta deficiente. Por lo cual, para ambas funciones se observa una concentración en el núcleo central y una disminución de demanda y cobertura hacia la periferia. Esto confirma que en el caso estudiado, y al igual que en otras localidades intermedias argentinas, se están generando procesos de menor accesibilidad, con menores ventajas de localización en estas áreas.

De igual forma esto implica que, si bien, en general, la oferta satisface a la demanda desde una perspectiva de mercado (tabla 2), no lo logra desde una perspectiva espacial. Analizando el mercado completo de transporte colectivo, se detecta que este opera con un pronunciado exceso de oferta (tabla 2), la capacidad diaria de la red supera ampliamente su demanda. Sin embargo, en este análisis no se considera la estacionalidad diaria propia del servicio, que implica un aumento de la demanda en las horas pico; ni la estacionalidad anual, que refiere a mayor demanda en algunos meses del año, como por ejemplo los meses escolares. Aunque la contrastación de oferta y demanda de acuerdo con estas consideraciones resultaría de interés, no está disponible la información necesaria para poder realizarla en el área en estudio. Así, se estima que, dado que existe una gran brecha y un exceso de oferta pronunciado, este se reduce ante los posibles aumentos de demanda mencionados, pero nunca se revierte hacia un exceso de demanda. Una de las justificaciones teóricas de este argumento es que en la planificación del sistema de transporte, dadas sus características particulares, se recomienda

Tabla 2. Capacidad diaria de la red

\begin{tabular}{|l|c|c|c|c|c|c|}
\hline & $\begin{array}{c}\text { Cantidad } \\
\text { de unidades } \\
\text { (flota) }\end{array}$ & $\begin{array}{c}\text { Capacidad total } \\
\text { de la flota (n. } \\
\text { de pasajeros) }\end{array}$ & $\begin{array}{c}\text { Frecuencia } \\
\text { promedio } \\
\text { (minutos) }\end{array}$ & $\begin{array}{c}\text { Cantidad de } \\
\text { recorridos } \\
\text { diarios }\end{array}$ & $\begin{array}{c}\text { Capacidad } \\
\text { diaria de } \\
\text { la red }\end{array}$ & $\begin{array}{c}\text { Pasajeros diarios } \\
\text { del transorte } \\
\text { colectivo }\end{array}$ \\
\hline $\begin{array}{l}\text { Trolebuses } \\
\text { y ómnibus }\end{array}$ & 993 & 39720 & 10,50 & 137 & 5447314 & 670000 \\
\hline
\end{tabular}

Fuente: elaboración propia con datos de la Encuesta de Origen y Destino (2010) y la Secretaría de Transporte de Mendoza (2017). 
Figura 3. Distribución espacial de la situación del mercado de transporte colectivo AMM

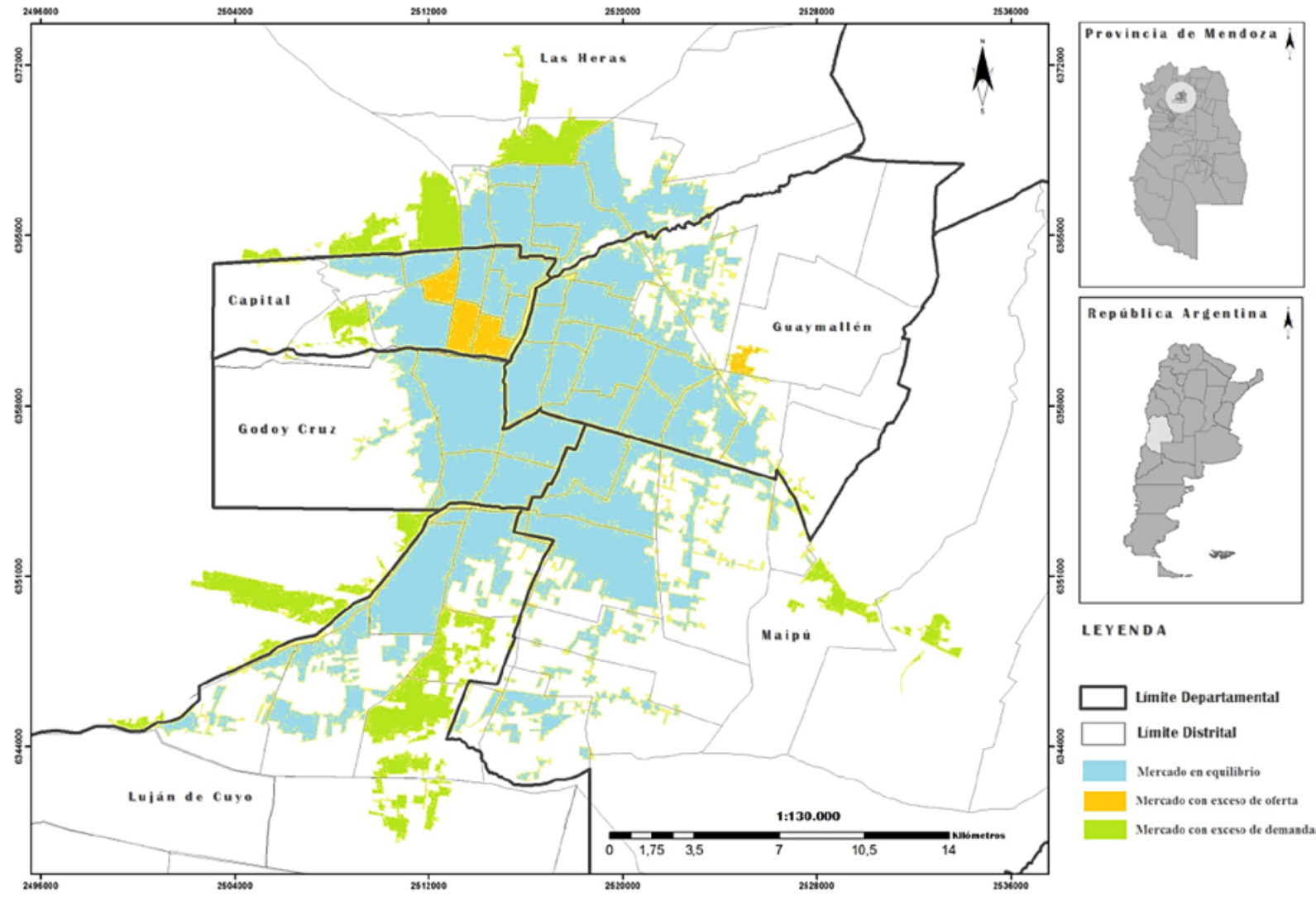

Fuente: elaboración propia con datos de PTuma (2011) y la Secretaría de Transporte de Mendoza (2017).

determinar el nivel de oferta a partir de los periodos de mayor demanda, dando como resultado un mercado en equilibrio $\mathrm{y}$, en los periodos de menor demanda un exceso de oferta. Esta situación de exceso de oferta resulta deseable.

No obstante, si se realiza una segmentación del transporte desde la dimensión espacial (figura 3), se observa que existen territarias 44 164 dando cuenta de deficiencias del servicio en estos territorios. Estadísticamente, se detecta que solo el $7 \%$ de los distritos presenta exceso de oferta, lo que implica que en los periodos de mayor demanda el servicio puede atender a la misma; el $77 \%$ se encuentra en equilibrio, por lo que en los momentos de mayor demanda podría existir un exceso de demanda, o áreas en las que hay exceso de demanda, sea, una deficiencia del servicio, y en el 
$17 \%$ de los distritos existe exceso de demanda, implicando un servicio ineficiente en la satisfacción de la demanda, que se pronuncia en los periodos de su incremento. Espacialmente, se evidencia que las áreas con exceso de oferta se ubican sobre todo en el área central del territorio urbano, mientras que aquellas con exceso de demanda se localizan en la periferia, mostrando una deficiencia del servicio de transporte colectivo en las áreas más alejadas del núcleo central.

Este diagnóstico espacial es una prueba de la falta de planificación integrada entre los usos del suelo y el sistema de movilidad, dando cuenta de un sistema de transporte pensado desde la oferta y no desde la demanda, con mayores requerimientos de movilidad por la reducción de la accesibilidad en las áreas periféricas.

\section{Reflexiones finales}

Desde una perspectiva teórica, las ciudades intermedias conservan características de sustentabilidad en tanto se desarrollan a escala humana contando con mayor accesibilidad y requiriendo, de este modo, menos movilidad. Esto resultaría posible de sostener en el tiempo a través de una planificación integrada entre usos del suelo y sistema de movilidad, pensando esta última desde la perspectiva de la demanda.

Lamentablemente, esta situación no es constante en todas las ciudades intermedias. En el área de estudio ocurre lo que en muchos otros territorios de porte medio. Existe una disminución de la accesibilidad en las áreas periféricas profundizada por una menor movilidad desde ellas, con el consecuente perjuicio para los residentes que no hacen uso del automóvil particular: grupos de menores ingresos, ancianos, niños, mujeres, ¿`casualidad?, en el análisis realizado quienes más demandan el servicio de transporte colectivo pertenecen a este grupo de población.

Se entiende, entonces, que existe necesidad por una política de usos del suelo y movilidad coordinada, que priorice el transporte colectivo, con el objetivo de hacerlo accesible y asequible para todos los habitantes del territorio. A partir del análisis realizado se detecta que existe una deficiencia del servicio en las áreas que más lo solicitan, en tanto que se concentra el mismo en el núcleo central.

Espacialmente, se evidencia que las áreas con exceso de oferta se ubican sobre todo en el área central del territorio urbano, mientras que aquellas con exceso de demanda se localizan en la periferia, mostrando un déficit del servicio de transporte colectivo en las áreas más alejadas del núcleo central. Esto da cuenta de una estructura de recorridos no óptima para la dimensión cuantitativa de la ciudad y, tampoco para su dinámica intrínseca y su rol en el sistema de ciudades. Siendo lo esperado, considerando la primacía de los recorridos radiales en un territorio en el que ya se estimaba la necesidad de otro tipo de rutas de transporte colectivo. 
El exceso de demanda implica que un grupo de población que necesita o desea utilizar este servicio en cualquier momento del día, para desarrollar sus actividades cotidianas, no puede hacerlo, por lo que se limitan sus posibilidades de movilidad. Esta carencia perjudica el desarrollo sostenible de la ciudad porque dificulta la conectividad e integración del territorio.

De igual forma, en este análisis se observa que tanto la oferta como la demanda se encuentran concentradas en el núcleo central de actividades y disminuyen su densidad hacia la periferia. Considerando que la relación de las funciones de oferta y demanda en el mercado de transporte colectivo tiene una naturaleza sistémica, se entiende que, si bien la demanda atrae a la oferta, esta última tira también de la demanda, específicamente haciendo referencia a la dimensión espacial. En el área estudiada se observa que es necesario llevar la oferta hacia las áreas en donde se halla el déficit, no obstante, es también relevante el ordenamiento del territorio urbano en términos de decidir hacia dónde y con qué características crece la ciudad para atraer allí la demanda del servicio. Esto último resulta una política pública fundamental para evitar o mitigar otros procesos urbanos negativos que, aunque incipientes en el territorio estudiado y en las ciudades intermedias en general, requiere de atención para conservar las características deseables de sostenibilidad.

\section{Referencias}

Alonso, W. (1964). Location and Land Use. Harvard University Press.

Anapolsky, S., \& Pereyra, L. (2012). Desafíos de la gestión y la planificación del transporte urbano y la movilidad en ciudades argentinas. Revista Transporte y Territorio, (7), 57-75. https:// doi.org/10.34096/rtt.i7.283

Ballabio, M. (2004). Los determinantes de selección individual de modo de transporte en la ciudad de Mendoza (Tesis de maestría). Flacso-México.

Bellet, C., \& Llop, J. M. (2004a). Miradas a otros espacios urbanos: las ciudades intermedias. Scripta Nova: Revista Electrónica de Geografía y Ciencias Sociales, 8(165), 1-28. http://hdl. handle.net/10459.1/41650

Bellet, C., \& Llop, J. M. (2004b). Ciudades intermedias: entre territorios concretos y ciudades y espacios globales. Ciudad y Territorio. Estudios Territoriales, 36(141-142), 569-582. https://dialnet.unirioja.es/servlet/ articulo? codigo $=1183999$

Bolay, J. C. (2020). Urban planning against poverty. How to think and do better cities in the global south. Springer Nature.

Bolay, J., \& Rabinovich, A. (2004). Ciudades intermedias: ¿una nueva oportunidad para un desarrollo regional coherente en América Latina?. En H. Dilla (Coord.), Globalización e intermediación urbana en América 
Latina (pp. 1-42). FLACSO-República dominicana.

Centro Tecnológico de Transporte, Tránsito y Seguridad Vial (C3T). (2016). Estudio del transporte público de pasajeros en ciudades de porte medio. Universidad Tecnológica $\mathrm{Na}$ cional. http://c3t.fra.utn.edu.ar/ wp-content/uploads/2016/10/Estudio-del-transporte-p\%C3\%BAblicode-pasajeros-en-ciudades-de-portemedio.-Versi\%C3\%B3n-Web.pdf

Cervero, R., \& Sesskin, S. (1995). An evaluation of the relationship between transit and urban form. TCRP Research Results Digest, (7). http:// onlinepubs.trb.org/onlinepubs/tcrp/ tcrp_rrd_07.pdf

Cervero, R. (2001). Integración del transporte y la planificación urbana. En M. Freire \& R. Stren (Eds.), Los retos del gobierno urbano (pp. 381-400). Banco Mundial; Alfaomega.

Ciudades y Gobiernos Locales Unidos (CGLU). (2016). Co-creando el futuro urbano. La agenda de las metrópolis, las ciudades intermedias y los territorios. UGCL-CGLU. https://www.uclg. org/sites/default/files/gold_iv_resumen_ejecutivo.pdf

Correa Díaz, G. (2010). Transporte y ciudad. Eure, 36(107), 133-137. http://dx.doi.org/10.4067/S025071612010000100008

De Rus, G., Campos, J., \& Nombella, G. (2003). Economía del transporte. Antoni Bosch.
DeIE. (2010). Censo Nacional de Población, Hogares y Vivienda. Dirección de Estadísticas e Investigaciones Económicas. http://www.deie.mendoza.gov.ar/\#!/censos-nacionalesde-poblacion $/ 2010$-censo-nacionalde-poblacion-hogares-y-vivienda-125 Ferré, C., Ferreira, F. H., \& Lanjouw, P. (2012). Is there a metropolitan bias? The relationship between poverty and city size in a selection of developing countries. The World Bank Economic Review, 26(3), 351-382. https://doi. org/10.1093/wber/lhs007

Flora, J. (2001). La administración del tránsito y el medio ambiente urbano. En M. Freire \& R. Stren (Eds.), Los retos del gobierno urbano (pp. 360371). Banco Mundial; Alfaomega.

Frick, A., \& Rodríguez-Pose, A. (2016). Average city size and economic growth. Cambridge Journal of Regions, Economy and Society, 9(2), 301318. https://doi.org/10.1093/cjres/ rsw013

Gakenheimer, R. (2006). Transporte y uso del suelo en los países en vía de desarrollo: planificas en medio de la controversia (ponencia). I Congreso Internacional sobre Desarrollo Humano. Madrid. http://www.reduniversitaria. es/ficheros/RalphGakemheimer(e). pdf

Gobierno de Mendoza. (2018). Área Metropolitana de Mendoza sostenible. Hacia un desarrollo sostenible del territorio. Ministerio del Interior, Obras 
Públicas y Vivienda. Presidencia de la Nación. https://n9.cl/ecqfw

Gutiérrez, A. (2012). ¿Qué es la movilidad? Elementos para (re) construir las definiciones básicas del campo del transporte. Revista Bitácora Urbano-Territorial, 21(2), 61-74. https://dialnet.unirioja.es/servlet/ articulo? codigo $=5001899$

Islas Rivera, V., Rivera Trujillo, C., \& Torres Vargas, G. (2002). Estudio de la demanda de transporte (Publicación técnica n. ${ }^{\circ} 213$ ). Secretaría de Comunicaciones y Transportes. Instituto Mexicano del Transporte. https:// www.imt.mx/archivos/Publicaciones/PublicacionTecnica/pt213.pdf

Kelly, B. (1994). The transportation-land use link. Journal of Planning Literature, 9(2), 128-145. https://doi. org/10.1177/088541229400900202

Lara, M. I. (2003). Un enfoque econométrico de los determinantes de la elección del modo de transporte: el caso del Gran Mendoza. Revista de la Facultad de Ciencias Económicas, 55(124), 105-126. https://bdigital. uncu.edu.ar/9118

Llop, J. M. (2014, 19 de junio). Las ciudades intermedias entre la gestión del crecimiento y sostenibilidad financiera. UCLG. https://www.uclg.org/en/no$\mathrm{de} / 22558$

Llop, J. M. (2008, julio). Ciudades intermedias, entre sus territorios y la globalización. Modulor, (5), 9-13.
Llop, J. M., Iglesias, B. M., Vargas, R., \& Blanc, F. (2019). Las ciudades intermedias: concepto y dimensiones. Ciudades, 22, 3-43. https://doi.org/10.24197/ciudades.22.2019.23-43

López, G. A., \& González González, M. J. (2019). Diffuse urbanisation and irregular urban growth: processes and trends in medium-sized cities in the Castilla and León region (Spain). Finisterra: Revista Portuguesa de Geografia, 54(112), 3-26. https://doi. org/10.18055/Finis17100

Maheshwari, B., Singh, V., \& Thoradeniya, B. (2016). Balanced urban development: options and strategies for liveable cities. Springer Open.

Martner Peyrelongue, C. (2015). Transporte y articulación urbano-rural de una ciudad intermedia mexicana. $R e-$ vista Mexicana de Sociologia, 77(2), 215-24l. http://www.scielo.org. $\mathrm{mx} /$ scielo.php? script $=$ sci_arttext $\& \mathrm{p}$ $\mathrm{id}=$ S0188-25032015000200002

Martner, C. (1996). Transporte y concentración territorial en América Latina: tendencias recientes. Ciudad y Territorio, (110), 651-661. https://dialnet.unirioja.es/servlet/ articulo? codigo $=177404$

Molinero Molinero, A. R., \& Sánchez Arellano, L. I. (2005). Transporte público: planeación, diseño, operación y administración. Universidad Autónoma del Estado de México. 
Moreno Quintero, E. (2011). Métodos de elección discreta en la estimación de la demanda de transporte (Publicación técnica n. $\left.{ }^{\circ} 335\right)$. Secretaría de Comunicaciones y Transportes. Instituto Mexicano del Transporte. https:// www.imt.mx/archivos/Publicaciones/PublicacionTecnica/pt335.pdf

Muth, R. (1969). Cities and Housing. University of Chicago Press.

Newman, P., \& Kenworthy, J. (1996). The land use-transportation connection. Land Use Policy, 13(1), 1-22. https://doi.org/10.1016/02648377(95)00027-5

Ortúzar, J. D., \& Willumsen, L. G. (2011). Modelling transport. John Wiley \& Sons.

PTUMA. (2011). Encuesta de Origen-Destino 2010: Movilidad en el Área Metropolitana de Mendoza. Ministerio del Interior y Transporte. Presidencia de la Nación. http://ingenieria.uncuyo. edu.ar/catedras/eodmendoza2010. pdf

Pulido, N. (2004). Globalización y surgimiento de ciudades "intermedias" en América Latina y Venezuela. Revista Geográfica Venezolana, 45(1), 91-121. http://erevistas.saber.ula.ve/ index.php/regeoven/article/viewFile/12339/21921923449

Punsola, A. (2014). El reto de la visibilidad. Ciudades Sostenibles, 18, 27-43.

Reta, C. (2007). Determinantes socioeconómicos de la demanda de transporte urbano en el Gran Mendoza. Encuesta
Origen Destino 2005. Asociación Argentina de Economía Política. https://aaep.org.ar/anales/works/ works2007/reta.pdf

Rode, P., \& Floater, G. (2014). Accessibility in cities: transport and urban form. LSE Cities. The New Climate Economy.

Rodríguez, V. (2002). Distribución territorial de la población de América Latina y el Caribe: tendencias, interpretaciones y desafíos para las politicas públicas (Serie Población y desarrollo n. $\left.{ }^{\circ} 32\right)$. Celade.

Roig, J. (2014). Las ciudades intermedias en la nueva agenda urbana. Revista Ciudad Sostenible, 18, 44-47.

Santos, L., \& De las Rivas, J. L. (2008). Ciudades con atributos: conectividad, accesibilidad y movilidad. Ciudades, (11), 13-32. https://doi.org/10.24197/ ciudades.11.2008.13-32

Secretaría de Transporte de Mendoza. (2017). Dirección de transporte. Gobierno de Mendoza. https://www. mendoza.gov.ar/transportes/

Shamsul Harumain, Y. A., \& Morimoto, A. (2013). Factors determining land use and transportation planning achievement in developing countries. The Sustainable City VIII, Urban Regeneration and Sustainability, 179(1), 315-325. https://doi.org/10.2495/ SC130271

Van Wee, B. (2013). Land use and transport. In B. Van Wee, J. A. Annema \& D. Banister (Eds.), The transport 


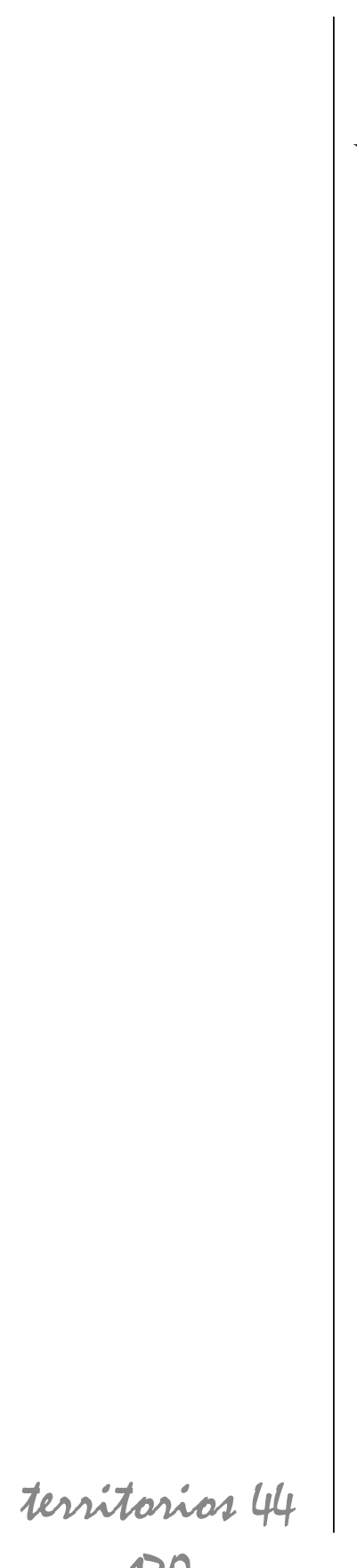

system and transport policy: an introduction (pp. 78-100). Edward Elgar Publishing.

Velázquez, C. (2015). Espacio público y movilidad urbana. Sistemas integrados de transporte masivo (Tesis doctoral). Universidad de Barcelona.
Vuchic, V. (2008). Transport systems and policies for sustainable cities. Thermal Science, 12(4), 7-17. https://doi. org/10.2298/TSCI0803007V

Vuchic, V. (1999). Transportation for Livable Cities. Routledge, Taylor and Francis Group. 